\title{
ESTILOS DE USO DO ESPAÇO VIRTUAL E REDES DIGITAIS DE APRENDIZAGENS: COAPRENDIZAGEM E INOVAÇÃO CURRICULAR NA EDUCAÇÃO BÁSICA
}

\author{
Maria do Rozario Gomes da Mota SILVA \\ Cláudia Simone Almeida de OLIVEIRA ${ }^{\mathrm{ii}}$ \\ Sérgio Paulino ABRANCHES ${ }^{\text {iii }}$
}

\begin{abstract}
RESUMO
Este estudo discute os Estilos de Uso do Espaço Virtual - EUEV, as implicações nas formas de aprender em redes digitais de aprendizagem e a contribuição para a coaprendizagem como possibilidade para inovação curricular na Educação Básica. O objetivo é analisar como os EUEV se expressam nas redes e contribuem para o desenvolvimento de competências digitais. A partir de Barros (2014); Okada (2011) e Almeida (2017), dentre outros, entendemos as redes de aprendizagem como espaços para novas aprendizagens e formas de aprender e como os Estilos de Aprendizagem - EA e os EUEV colaboram para um currículo inovador para a Educação Básica. O estudo apontou que a Educação Básica precisa estar aberta às novas descobertas e conhecimentos que envolvam os novos cenários de aprendizagem e formas de aprender em rede, e os EA e EUEV dos estudantes como elementos essenciais no desenvolvimento das competências digitais para coaprender e cocriar em rede.
\end{abstract}

PALAVRAS-CHAVE: Estilos de uso do espaço virtual; Redes digitais de aprendizagem; Coaprendizagem; Inovação Curricular.

\section{VIRTUAL SPACE USE STYLES AND DIGITAL LEARNING NETWORKS: CO-LEARNING AND CURRICULAR INNOVATION IN BASIC EDUCATION}

\begin{abstract}
This study discusses the Virtual Space Use Styles - VSUS, its implications in the ways of learning in digital learning networks and its contribution to co-learning as a possibility for curricular innovation in Basic Education. The objective is to analyze how the VSUS are expressed in networks, and how these styles contribute to the development of digital competences. As of the studies by Barros (2014); Okada (2011) e Almeida (2017), among others, we understand about learning networks as spaces for new learning and ways of learning them; how Learning Styles: LS and VSUS can collaborate in an innovative curriculum for Basic Education. The study pointed out that Basic Education needs to be open to new discoveries and knowledge involving new learning scenarios and ways of learning in a network, and the students' LS and VSUS as essential elements in the development of digital skills to co-learn and cocreate in a network
\end{abstract}

KEYWORDS: Virtual space use styles; Digital learning networks; Co-learning; Curricular Innovation.

\footnotetext{
${ }^{i}$ Doutorado em Educação Matemática e Tecnológica pela Universidade Federal de Pernambuco. Professora da Secretaria de Educação do Recife-PE. E-mail: rozariogms@gmail.com.

ii Doutorado em Educação Matemática e Tecnológica pela Universidade Federal de Pernambuco. Professora e Técnica pedagógica da Secretaria de Educação do Recife-PE. E-mail: cacalsimone38@ gmail.com.

iii Doutorado em Educação pela Universidade de São Paulo. Professor da Universidade Federal de Pernambuco. E-mail: sergio.abranches@gmail.com.
} 

APRENDIZAJE E INNOVACIÓN CURRICULAR EN LA EDUCACIÓN BÁSICA

\section{RESUMEN}

Este estudio analiza los Estilos de Uso del Espacio Virtual - EUEV, las implicaciones sobre las formas de aprendizaje en las redes digitales de aprendizaje y la contribución al co-aprendizaje como posibilidad de innovación curricular en Educación Básica. El objetivo es analizar cómo las EUEV se expresan en redes y contribuyen al desarrollo de las competencias digitales. Apoyados en Barros (2014); Okada (2011) y Almeida (2017), entre otros, entendemos las redes de aprendizaje como espacios para nuevos aprendizajes y formas de aprender y cómo los Estilos de Aprendizaje - EA y EUEV colaboran para un currículo innovador para la Educación Básica. El estudio señaló que la Educación Básica debe estar abierta a nuevos descubrimientos y conocimientos que involucren nuevos escenarios de aprendizaje y formas de aprendizaje en red, y la EA y EUEV de los estudiantes como elementos esenciales en el desarrollo de habilidades digitales para coaprender y co-crear en red.

PALABRAS CLAVE: Estilos de uso del espacio virtual; Redes de aprendizaje digital; Co-aprendizaje; Innovación curricular.

\section{INTRODUÇÃO}

Este trabalho tem como base duas pesquisas de doutorado, que tiveram como lócus uma rede de pesquisa, denominada "Rede de Pesquisa Colaborativa Universidade Escola". A primeira pesquisa analisou as características e os elementos que caracterizaram e retroalimentaram essa rede e suas implicações no currículo escolar. A segunda analisou como os Estilos de Uso do Espaço Virtual - EUEV interferiram na atuação dos estudantes, usuários desta rede, e como tal atuação interferiu nas formas de aprender no contexto dessa rede de aprendizagem.

Neste estudo, discutimos os Estilos de Uso do Espaço Virtual - EUEV, suas implicações nas formas de aprender no contexto de redes de aprendizagem e sua contribuição para o desenvolvimento da Coaprendizagem ${ }^{1}$ como possibilidades para a inovação curricular na Educação Básica.

Para isso, aprofundamos a compreensão sobre redes digitais de aprendizagem como espaços para novos sabres, novas aprendizagens e formas de aprender; sobre como a teoria dos Estilos de Aprendizagem - EA e a teoria dos EUEV podem colaborar na compreensão do processo de ensino e aprendizagem na perspectiva da coaprendizagem; e, sobre as implicações dos EUEV e das redes digitais de aprendizagens na perspectiva de um currículo mais aberto e inovador para a Educação Básica. Essas questões envolvem espaços, posturas, relações, 
infraestrutura e tecnologias, que, por sua vez, repercutem na utilização de novas didáticas e metodologias que se aliam a esse currículo mais inovador, propiciando ao estudante mais autonomia e mais protagonismo em sua aprendizagem.

Partimos do pressuposto que as redes digitais de aprendizagem podem configurar-se como espaços de aprendizagem propício para inovar as formas de aprender, influenciando os estilos de aprendizagem e os EUEV. No contexto das redes digitais de aprendizagem, esses estilos são dinamizados, apontando para maior colaboração no processo de aprender dos estudantes. Esses estilos também interferem na dinâmica das redes, fazendo com que sejam mais abertas e mais centrais na aprendizagem desses sujeitos, interferindo nas questões curriculares.

As redes digitais de aprendizagem se caracterizam como um espaço fértil para a aprendizagem colaborativa e para a coaprendizagem. Os estudantes, se bem orientados, passam a ser colaboradores do seu próprio processo de aprendizagem, de acordo com seus EA e com seus EUEV. A partir de um currículo inovador, os estudantes podem buscar nas redes informações e conteúdos para construção coletiva de novos saberes, de maneira participativa, onde todos são parceiros nesse processo colaborativo de aprender, compreender e construir significados.

Nosso principal objetivo é discutir como os EUEV se expressam nas redes, em relação às novas formas de aprender; como estes estilos podem contribuir para o desenvolvimento das competências digitais para a Coaprendizagem e quais as repercussões para a inovação curricular na Educação Básica.

Os resultados apresentam um contributo significativo para o pensamento sobre a teoria dos Estilos de Uso do Espaço Virtual e o desenvolvimento das competências digitais emergentes, considerando as características e os elementos diferenciadores para uma educação inovadora, que atenda às demandas do estudante dos tempos atuais e que amplie as relações entre as novas formas de aprender em rede e a inovação curricular, onde os estudantes passam a ser colaboradores do seu próprio processo de aprendizagem, de acordo com seus estilos de aprendizagem.

A partir desse cenário, a pergunta que surge é: como pensar novos cenários de aprendizagem para a Educação Básica, de modo a atender às necessidades dos estudantes que convivem em rede, em relação às suas formas e estilos de aprender no mundo contemporâneo, visando à coaprendizagem a partir de um currículo inovador? Para 
respondermos esta questão, precisamos dialogar com alguns temas e conceitos que envolvem a teoria dos Estilos de Aprendizagem; a teoria dos Estilos de Uso do Espaço Virtual; os estilos de coaprendizagem; metodologias de ensino e aprendizagem utilizando o ciberespaço e que permitam a Coaprendizagem e a Coinvestigação; competências digitais para coaprender e coinvestigar em rede; inovação curricular e saber escolar no mundo contemporâneo.

A partir dessa discussão, apresentaremos reflexões acerca de práticas pedagógicas para Educação Básica que envolvam a aprendizagem em rede, considerando o espaço virtual como cenário propício para coaprendizagem e coinvestigação, além da possibilidade de ampliar e potencializar as novas formas de aprender dos estudantes de acordo com as suas demandas quanto às formas e aos estilos de aprender no mundo contemporâneo e que utilizem um currículo mais aberto e flexível.

\section{REVISÃO DA LITERATURA}

As pesquisas que tratam de Redes de Aprendizagens e Aprendizagem em Redes têm como principais características a análise das novas formas de construir conhecimento e de aprender em rede. Apresentam as redes como espaços comunicacionais abertos de interação, colaboração e partilha.

O espaço de aprendizagem em rede pode fornecer suporte contínuo ao ambiente de aprendizagem e deve combinar as vantagens do ensino no virtual e no presencial (WANG, 2019). Segundo Bedin (2017), as interações influenciam de forma positiva nas redes, pois possuem características que se assemelham ao ensino presencial, como debate, compartilhamento e confronto de ideias, dentre outras formas de construir conhecimento pela colaboração e troca. Com os mecanismos e recursos tecnológicos disponíveis nas redes, ampliam-se as possibilidades dessa troca de ideias, promovendo a aprendizagem colaborativa, permitindo a partilha e o aperfeiçoamento de conteúdos em múltiplos suportes.

Quando os estudantes sentem que é fácil usar as redes para aprender, eles sentem prazer em fazê-lo e, depois, percebem essas redes como ferramenta útil na aprendizagem. O senso de pertencimento à rede faz com que se sintam menos isolados e, eventualmente, passam a ter um maior nível de satisfação, em que a presença social tem influência positiva na satisfação e no sentimento de pertencer (OOI et al., 2018) 
As pesquisas sobre os estilos de aprendizagem ampliaram o conhecimento sobre as formas de aprender, de acordo com as competências e habilidades pessoais do indivíduo. Assim, a teoria dos EA e a teoria dos EUEV colaboram na compreensão do processo de ensino e aprendizagem, pois consideram as diferenças individuais, e quanto maior a variedade de formas de assimilação de conteúdos, melhor se consegue aprender e construir conhecimentos, de acordo com as exigências do mundo atual.

Partindo das reflexões de Alonso, Gallego e Honey (2002), que apresentam os EA como formas individuais com que cada sujeito aprende melhor, entendemos as diferentes formas de aprender usando tecnologia, tanto no presencial como no virtual, servindo de base para os estudos sobre EUEV (BARROS, 2011).

Barros (2014) apresenta um estudo que busca entender como as tecnologias digitais de informação e comunicação (TDIC) podem contribuir para as necessidades, habilidades, aspirações e circunstâncias dos estudantes e das comunidades de aprendizagem. Ressalta que as competências digitais correspondem à capacidade de mobilizar processos coletivos; capacidade de busca e pesquisa de informação; capacidade de organização e estruturação lógica de processos; capacidade de produção de um artefato ou conteúdo. Para a autora, o processo de coaprendizagem é enriquecido pela ampla participação para cocriar, readaptar e reutilizar conteúdos e estratégias para aprender, de forma aberta, colaborativa, interativa e participativa.

Terçariol e Barros (2017) verificaram os EUEV a partir do uso criativo dos espaços online, em especial das redes sociais. As autoras refletem sobre como se aprende de forma colaborativa em rede e, a partir daí, como se origina a coaprendizagem, na perspectiva da aprendizagem em rede, a partir das características de cada EUEV. Isto ajuda a compreender o impacto do uso das redes digitais nas formas de aprender no virtual e suas relações com os EUEV dos estudantes, para identificarmos e construirmos práticas inovadoras nas comunidades e redes de aprendizagem em um currículo aberto e inovador.

Sobre inovação curricular, Degrandis e Marques (2018) apontam para uma urgência no atendimento às necessidades educativas da contemporaneidade, que implicam mudanças em quatro dimensões: metodológica, avaliativa, espaço temporal e perfil profissional. Neste sentido, assumimos neste trabalho que a inovação curricular não se limita à incorporação de novos elementos ao currículo escolar pré-estabelecido, tal como a simples introdução de tecnologias na prática pedagógica. A inovação curricular trata propriamente da integração das dimensões acima apontadas, em acordo com que Degrandis e Marques (2018) anunciam. 
Essas dimensões foram contempladas de forma inovadora na Rede de Pesquisa Colaborativa Universidade Escola, em que na dimensão metodológica, utilizaram-se a pedagogia de projetos de aprendizagem e a interdisciplinaridade.

Essa proposta veio alinhada a uma nova perspectiva avaliativa, na medida em que previa um currículo aberto, na web, organizado a partir de um tema gerador e dentro de uma abordagem interdisciplinar. As pesquisas desenvolvidas pelos estudantes foram utilizadas por professores para o processo avaliativo/curricular da escola.

Com relação ao espaço temporal, percebemos que ao romper com o espaço unidirecional, algumas "fronteiras" foram ultrapassadas e professores e estudantes planejaram juntos dando novo tratamento aos conteúdos, contextualizando e incentivando outras narrativas possíveis para a construção do conhecimento.

Com relação à última dimensão, o perfil dos professores contribuiu para o desenvolvimento da rede de aprendizagem, pois eram mestres e/ou especialistas, de diferentes áreas do conhecimento, empenhados em despertar nos estudantes o interesse pelo trabalho com projetos, participação, colaboração e articulação e construção de aprendizagens em rede.

\section{AS REDES DIGITAIS COMO NOVOS ESPAÇOS DE APRENDIZAGEM NA EDUCAÇÃO BÁSICA}

As discussões acerca do conceito de espaços de aprendizagem vêm crescendo, com uma nítida tendência para utilização do espaço virtual em rede, como novos cenários de aprendizagem, que podem ter um impacto direto no processo de ensino, contribuindo com a aprendizagem significativa dos estudantes da era digital. A partir das reflexões apresentadas sobre esses novos cenários, discutimos possibilidades de novos designs e estratégias pedagógicas para Educação Básica, contribuindo assim para a transformação efetiva da prática docente e para a aprendizagem significativa no contexto educacional da era digital, considerando os EA como preferências individuais e intransferíveis no processo, assim como a sua importância no contexto educacional atual com o uso das tecnologias.

Percebemos que apesar do surgimento de novas abordagens pedagógicas e metodológicas na educação, o desenho dos espaços das salas de aula pouco mudou e tendem a enfraquecer o poder que essas novas práticas exercem sobre o currículo e os EA dos estudantes. 
Com o passar do tempo e com as novas modalidades de educação não presenciais, o conceito de aula e o de sala de aula também sofreram alterações em conformidade com essas transformações, da mesma forma que a aprendizagem, que hoje não está mais restrita à instituição educacional e muito menos à sala de aula. A aprendizagem pode ocorrer em qualquer lugar e esse lugar, físico ou virtual, pode ser transformado num espaço de aprendizagem.

As redes virtuais se configuram um espaço propício para essas novas formas de aprendizagens. O principal desafio é desenvolver competências e habilidades específicas para promover práticas de mediação efetivas para facilitar estas formas de aprendizagens. Os alunos de hoje, os ditos nativos/residentes digitais ${ }^{2}$, consideram a Internet seu universo de informações mais importante. E, ao invés de tentar saber tudo, estudantes e professores confiam em redes de pares e bases de dados de informação.

Mas a aprendizagem continua sendo a atividade central das instituições de ensino. $\mathrm{O}$ espaço - seja físico ou virtual - pode ter um impacto na aprendizagem. Pode servir para integrar as pessoas, pode incentivar a exploração, a colaboração e o diálogo, mas, também, pode transportar uma mensagem de silêncio e desconexão (OBLINGER, 2006). De acordo com Oblinger (2006), os espaços têm que refletir as pessoas dentro do seu tempo atual; entretanto os espaços de aprendizagem, principalmente as salas de aula, não condizem com os estudantes da atualidade. Os estudantes da nossa era são mais ativos, interativos, participativos, colaborativos e altamente motivados e conectados em redes. Assim, o comportamento do estudante deve corresponder aos seus estilos e às preferências de aprendizagem.

$\mathrm{O}$ conceito de Aprendizagem que adotamos está relacionado com o conceito de desenvolvimento integral do ser humano, em suas diferentes esferas: cognitiva, sensitiva, de competências e de atitudes ou valores. Em um processo de aprendizagem, o aluno assume um papel ativo e participante (não mais passivo e repetidor), protagonista de ações que o levam a aprender e a mudar seu comportamento. "Essas ações, ele as realiza sozinho (autoaprendizagem), com o professor e com os seus colegas (interaprendizagem). (...). Estas interações (aluno-professor-alunos) conferem um pleno sentido à co-responsabilidade no processo de aprendizagem" (MASETTO, 2000, p. 141).

Quanto mais entendermos a respeito de como nossos estudantes aprendem e sobre seus EA, mais mudaremos nossas concepções e perspectivas de espaços de aprendizagem. Para atender às demandas de aprendizagem desses estudantes da era digital, estes espaços de aprendizagem devem ser cada vez mais flexíveis e interconectados em rede, que possibilitem 
reunir atividades formais e informais, que reconheçam que a aprendizagem pode ocorrer em qualquer lugar, a qualquer momento, em espaços físicos ou virtuais.

As redes interferem diretamente na forma como processamos e damos significados às informações que recebemos, pois os modos como as informações circulam e chegam até nós representam um novo ambiente cognitivo, característico da era digital, em que o pensamento é elaborado, processado e experimentado a uma velocidade muito diferente da que seria possível antes dessa era (MARTINO, 2015). O maior desafio continua sendo transformar a mera informação em conhecimento através de uma postura crítica e reflexiva.

Pensando sobre as diferentes formas de aprender em rede a partir dos EUEV, entendemos que o conhecimento se constrói através de uma rede de conexões, tendo em vista que a experiência de aprendizagem, ela mesma, pode definir-se como o momento em que adquirimos, de forma ativa, o conhecimento que nos faltava para completarmos uma tarefa necessária ou resolvermos um problema. Assim, na cultura digital, o conhecimento está disponível através de redes e o ato de aprender constitui-se a capacidade de construir uma ampla rede de conexões, ou seja, aprender é criar redes e também navegar por redes (SILVA, 2020).

O uso das redes sociais no desenvolvimento de projetos pedagógicos vem crescendo cada vez mais. Aos poucos, as redes começam a ser exploradas como meio para auxiliar professores e alunos nos processos de ensino e aprendizagem. Podem ser utilizadas como ferramentas pedagógicas para o ensino e aprendizagem em grupo, permitindo ao estudante e ao professor a flexibilidade do tempo e do espaço para ensinar e aprender, extrapolando os limites da sala de aula (VALENTE, 2011).

O conceito que adotamos para rede digital de aprendizagem corresponde a um ambiente virtual, composto por uma comunidade de estudantes e professores que aprendem juntos de forma aberta e compartilhada, trocando experiências e conhecimentos, de maneira interativa e colaborativa, ou seja, a base da rede de aprendizagem é a colaboração, envolvendo a articulação complexa, dialógica, criativa, reflexiva e democrática, em que a mobilidade do conhecimento é a maior riqueza para as redes de aprendizagens colaborativas, a partir de redes de relações com intencionalidade educativa (OLIVEIRA, 2018).

As redes digitais de aprendizagem se caracterizam como um espaço fértil para a aprendizagem colaborativa e para a coaprendizagem. No ambiente de rede, os professores podem orientar os estudantes de forma que eles passem a ser colaboradores do seu próprio 
processo de aprendizagem, considerando seus estilos de aprendizagem e seus Estilos de Uso do Espaço Virtual predominantes. As redes de aprendizagens também se oferecem como espaço propício para trabalharmos um currículo mais inovador, em que os estudantes possam buscar nas redes informações e conteúdos para construção coletiva de novos saberes, de maneira participativa, onde todos sejam parceiros nesse processo colaborativo de aprender, compreender e construir significados (SILVA; OLIVEIRA; ABRANCHES, 2019).

Já a aprendizagem em rede é uma forma específica de aprender, apoiada pelo suporte contínuo do ambiente de rede de aprendizagem, de forma a oportunizar aos estudantes a possibilidade de combinar as vantagens do ensino online e presencial. A aprendizagem em rede oportuniza maior autonomia de aprendizagem e maior liberdade ao estudante para organizar os conteúdos de aprendizagem e seu progresso de acordo com suas competências, habilidades e tempo. Isso requer do aluno autodisciplina para planejar e organizar o aprendizado, os conteúdos e a prática, tendo efeito significativo na melhoria do processo de ensino e aprendizagem.

Pensar nas redes digitais como novos espaços de aprendizagem para a Educação Básica implica pensarmos o desenvolvimento de um ambiente virtual que contemple os diversos cenários, elaborados pedagogicamente por uma equipe multidisciplinar que contemple as dimensões técnicas e pedagógicas necessárias ao processo de ensino e aprendizagem, onde estudantes e professores troquem informações e conhecimentos e aprendam com seus pares, em rede, de forma aberta, participativa e colaborativa.

As redes digitais vêm se destacando como uma nova modalidade de comunicação e interação na internet e isso implica nas formas de veiculação de informação na web. O poder de uso da web para autoria e download de conteúdos tem favorecido a cultura do conhecimento e a aprendizagem em rede. Nas redes, é possível pesquisar informações nos mais diferentes sites de busca, portais educacionais, blogs, cursos, exames e simulados on-line, entre outros. A partir da busca online, os usuários da rede também podem compartilhar as informações encontradas e os conhecimentos adquiridos (SILVA, 2020).

A partir dessa compreensão de rede e de rede de aprendizagem, analisamos os EUEV e as competências digitais para o desenvolvimento da coaprendizagem em rede, compreendendo que as redes de aprendizagem funcionam como espaços para novas aprendizagens e formas de aprender. Assim, indicamos possibilidades para o uso dessas redes, como um espaço que se 
converte em um leque de complexidades e que está intrinsecamente relacionado aos EUEV dos estudantes.

\section{ESTILOS DE USO DO ESPAÇO VIRTUAL E AS COMPETÊNCIAS DIGITAIS PARA O DESENVOLVIMENTO DA COAPRENDIZAGEM EM REDE}

As transformações na educação formal em função da sociedade em rede fazem emergir a necessidade de desenvolver no estudante as competências digitais para Coaprender e Coinvestigar no contexto das redes digitais. As pesquisas sobre os EA ampliaram o conhecimento sobre as formas de aprender, de acordo com as competências e habilidades pessoais do indivíduo. Dessa forma, tanto a teoria dos EA como a teoria dos EUEV colaboram na compreensão do processo de ensino e aprendizagem no contexto das redes digitais, pois consideram as diferenças individuais, e, quanto maior a variedade de formas de assimilação de conteúdos, melhor se consegue aprender e construir conhecimentos, de acordo com as exigências do mundo atual.

O foco da nossa discussão envolve as formas de aprender em redes digitais de aprendizagem e os EA no ambiente virtual. Sua importância está exatamente em identificar como se aprende em rede de forma colaborativa e suas implicações para a Coaprendizagem. Os EA dizem respeito às maneiras pessoais de processar informação, sentimento e comportamento em contextos de aprendizagem.

Conforme Alonso, Gallego e Honey (2002), existem quatro estilos de aprendizagem já bem definidos:

O ativo - os sujeitos são mais ágeis, gostam dos desafios que envolvem novas experiências e não gostam de grandes prazos. No virtual, de acordo com Barros (2014), as ações desenvolvidas estão voltadas ao buscar, participar, acessar, encontrar e localizar.

O reflexivo - os sujeitos são mais analíticos, gostam de considerar todas as alternativas possíveis antes de realizar algo. No virtual, de acordo com Barros (2014), as ações desenvolvidas estão voltadas ao investigar, analisar, observar, interpretar e adquirir.

O teórico - os sujeitos são mais lógicos, tendem a ser perfeccionistas; integram o que fazem em teorias coerentes; analisam e sintetizam; são profundos. No virtual, de acordo com Barros (2014), as ações desenvolvidas estão voltadas ao planejar, estruturar, construir, 
organizar e selecionar.

O pragmático - os sujeitos são mais práticos, gostam de atuar rapidamente e com seguridade com aquelas ideias e projetos que os atraem. No virtual, de acordo com Barros (2014), as ações desenvolvidas estão voltadas ao realizar, elaborar, usar, praticar e experimentar.

Com base na Teoria dos Estilos de Aprendizagem, em conjunto com as reflexões acerca das formas como as pessoas aprendem no virtual e sua caracterização, Barros (2011) desenvolveu os EUEV e suas referências. Para a autora, "o virtual influencia decisivamente em cada um dos estilos de aprendizagem e promove mudanças determinantes na forma de aprender" (2011, p. 89-90).

Barros (2011) identificou como as pessoas aprendem no espaço virtual e quais os elementos indispensáveis para que a aprendizagem ocorra nesse espaço; não identificou novos estilos de aprendizagem característicos desse espaço, mas revelou como as pessoas, segundo os diversos Estilos de Aprendizagem existentes, utilizam o espaço virtual para aprender. Assim, define os EUEV como os estilos de uso das ferramentas, recursos e aplicativos online, e estão diretamente relacionados ao planejamento individual do uso, que repercute na forma de buscar as informações, na forma de interagir com textos e imagens e na convergência de mídia no virtual.

Barros (2014) apresenta como as TDIC podem contribuir para o desenvolvimento das competências digitais, considerando as necessidades, habilidades, aspirações e circunstâncias dos estudantes e das comunidades de aprendizagem. Ressalta que as competências digitais correspondem à capacidade de mobilizar processos coletivos; capacidade de busca e pesquisa de informação; capacidade de organização e estruturação lógica de processos; capacidade de produção de um artefato ou conteúdo. Para a autora, o processo de Coaprendizagem é enriquecido pela ampla participação para cocriar, readaptar e reutilizar conteúdos e estratégias para aprender, de forma aberta, colaborativa, interativa e participativa.

Silva (2020) analisou como os EUEV interferem na atuação dos estudantes e como tal atuação interfere nas formas de aprender no contexto de redes digitais de aprendizagem. A partir dos elementos e das características de cada EUEV dos estudantes, a autora apresentou reflexões sobre como se aprende de forma colaborativa no ambiente de rede de aprendizagem e como se origina a Coaprendizagem no contexto da aprendizagem em rede. Isso nos auxilia na compreensão sobre as implicações que o uso das redes digitais ocasiona nas formas de aprender 
Programa de Pós-Graduação em Educação: Currículo

no virtual e suas relações com os EUEV dos estudantes, para que assim possamos identificar práticas pedagógicas inovadoras para comunidades e redes de aprendizagem, possibilitando a adoção de um currículo mais aberto e inovador na Educação Básica.

Barros (2011) categorizou quatro tendências de uso do espaço virtual, denominadas como: estilo de uso participativo no espaço virtual - Nível A; estilo de busca e pesquisa no espaço virtual - Nível B; estilo de estruturação e planejamento do espaço virtual - Nível C; estilo concreto e de produção no espaço virtual - Nível D. Assim, cada EUEV apresenta uma relação com os EA e com as ações desenvolvidas no espaço virtual, a partir dos elementos e das características específicas de cada estilo, conforme quadro a seguir:

Quadro 1 - Relações entre os EA e EUEV em função das ações e dos elementos e das características do espaço virtual

\begin{tabular}{|c|c|c|c|}
\hline EA & EUEV & $\begin{array}{c}\text { AÇÕES } \\
\text { RELACIONADAS }\end{array}$ & ELEMENTOS/CARACTERÍSTICAS \\
\hline $\begin{array}{c}\text { ATIVO } \\
\text { (mais ágeis) }\end{array}$ & $\begin{array}{c}\text { USO } \\
\text { PARTICIPATIVO }\end{array}$ & $\begin{array}{l}\text { buscar, participar, } \\
\text { acessar, encontrar e } \\
\text { localizar }\end{array}$ & $\begin{array}{ll}\text { - } & \text { Participação } \\
\text { - } & \text { Aprendizagem colaborativa }\end{array}$ \\
\hline $\begin{array}{l}\text { REFLEXIVO } \\
\text { (mais analítico) }\end{array}$ & $\begin{array}{l}\text { BUSCA E } \\
\text { PESQUISA }\end{array}$ & $\begin{array}{l}\text { investigar, analisar, } \\
\text { observar, interpretar } \\
\text { e adquirir }\end{array}$ & $\begin{array}{l}\text { - } \quad \text { Pesquisa online } \\
\text { - } \quad \text { Apoio para a coaprendizagem }\end{array}$ \\
\hline $\begin{array}{l}\text { TEÓRICO } \\
\text { (mais lógico) }\end{array}$ & $\begin{array}{l}\text { ESTRUTURAÇÃO } \\
\text { E } \\
\text { PLANEJAMENTO }\end{array}$ & $\begin{array}{l}\text { planejar, estruturar, } \\
\text { construir, organizar } \\
\text { e selecionar }\end{array}$ & $\begin{array}{l}\text { - Atividades de planejamento e } \\
\text { elaboração de conteúdos } \\
\text { Organização e planejamento de } \\
\text { participações e dos seus } \\
\text { resultados para a aprendizagem } \\
\text { colaborativa }\end{array}$ \\
\hline $\begin{array}{l}\text { PRAGMÁTICO } \\
\text { (mais prático) }\end{array}$ & $\begin{array}{c}\text { AÇÃO } \\
\text { CONCRETA E DE } \\
\text { PRODUÇÃO }\end{array}$ & $\begin{array}{l}\text { realizar, elaborar, } \\
\text { usar, praticar e } \\
\text { experimentar }\end{array}$ & $\begin{array}{ll}\text { - } & \text { realização dos serviços online e } \\
\text { viabilização com rapidez } \\
\text { - } \quad \text { produz e apresenta algo concreto }\end{array}$ \\
\hline
\end{tabular}

Fonte: Silva (2020, p. 71)

Em relação ao conceito de Coaprendizagem, Okada (2014, p. 15) define como

O conceito "Coaprender", do acrônimo em inglês "Colearn" cujo significado é "Collaborative Open LEARNing" significa aprendizagem aberta colaborativa. Na etimologia, o prefixo "co" significa "junto", "a par", "parceria", então, resultando em "aprendizagem em conjunto". A aprendizagem nas redes digitais caracterizadas pela abertura de conhecimento e construção colaborativa é uma das bases da Educação do século XXI.

No contexto de redes, a Coaprendizagem ganha destaque nas ações colaborativas. As 
principais características em relação à Coaprendizagem são: 1) gostar de participar e realizar trabalhos em grupos online, buscar situações online, participar em fóruns de discussão; 2) Gostar de pesquisar e buscar informação; 3) organizar e planejar a participação; 4) concretizar e produzir a partir dos resultados da aprendizagem. No cenário de redes de aprendizagem, a identificação dessas características de Coaprendizagem e a estruturação de atividades que contemplem todos os Estilos de Aprendizagem e EUEV, a partir de um currículo aberto e flexível, compartilhado pelos usuários, ampliam as possibilidades e os recursos para o desenvolvimento da própria aprendizagem em rede.

Okada (2011) salienta a importância da web 2.0 como um grande espaço aberto de inteligência coletiva, em que seus membros (docentes, pesquisadores ou estudantes) passam a ser coautores criativos, coaprendizes críticos e coprodutores colaboradores em suas redes sociais de ensino-aprendizagem. A autora destaca que "a Co-aprendizagem 2.0 visa o enriquecimento da educação formal e também da educação informal via o uso de inúmeros recursos, tecnologias e metodologias para ampliar a inter-autonomia e participação ativa e colaborativa do aprendiz" (OKADA, 2011, p. 9).

Okada (2012) destaca a necessidade de desenvolver competências e habilidades mais avançadas, tirando proveito dos benefícios de Coaprendizagem nos espaços colaborativos da Web 2.0. A Coaprendizagem nas redes depende dessas competências digitais para o seu desenvolvimento. Para Okada (2014), a abertura e a colaboração são consideradas as duas bases principais para a Coaprendizagem. A autora destaca a necessidade de se desenvolver habilidades técnicas a fim de se beneficiar do espaço digital para a aprendizagem e o desenvolvimento.

Barros (2014) relaciona as competências digitais desenvolvidas no espaço virtual, em função de cada EUEV com as competências para Coaprender e Coinvestigar através dos papéis desempenhados pelos usuários da rede. Assim, a capacidade de mobilizar processos coletivos implica o desenvolvimento de papéis mais proativo e interativo na rede. A capacidade de buscar e pesquisar informação implica o desenvolvimento de papéis mais técnico, reflexivo e científico na rede. A capacidade de organização e estruturação lógica de processos implica o desenvolvimento de papéis mais empreendedor, técnico e reflexivo. A capacidade de produção de um artefato ou conteúdo implica o desenvolvimento de papéis mais técnico, reflexivo, científico e inovador. Em um contexto de rede de aprendizagem, as características de Coaprendizagem dos estudantes e as competências para coaprender e cocriar podem facilitar 
a dinâmica da coletividade e a construção conjunta do conhecimento.

$\mathrm{O}$ ensino e a aprendizagem no contexto de redes digitais de aprendizagem exigem bases fundamentadas em novos paradigmas, em que o processo de ensino e aprendizagem ocorra de maneira mais horizontal, desprovido de uma hierarquia mais rígida; utilize metodologias ativas e dinâmicas participativas, que considerem os EA e EUEV durante o processo de aprendizagem, possibilitando uma aprendizagem mais significativa do sujeito, estimulando a autonomia e o protagonismo; e, que considere um currículo aberto, flexível, organizado a partir de temas geradores e dentro de uma abordagem interdisciplinar.

\section{CURRÍCULO EM REDE PARA A COAPRENDIZAGEM}

O primeiro destaque de uma rede de aprendizagem é a gestão compartilhada. O outro aspecto é considerar a rede como espaço híbrido, online, mas também com momentos presenciais em novos contextos de aprendizagem flexível, no espaço digital e aberto à integração de novos nós, acessível porque todos podem compartilhar experiências, ou seja, "participar da reconstrução de conceitos e relacionar-se com outros contextos e lugares físicos ou virtuais, que se entrelaçam formando um espaço híbrido de conexões e fluxos de informações, pessoas, conhecimentos cotidianos e científicos de distintas áreas" (ALMEIDA, 2017, p. 10).

Sabemos que currículo é um conceito polissêmico, não apenas uma proposta institucional e sistematizada, mas também uma preparação para a vida. Sendo assim, mesmo diante da sua variedade de concepções e formas, nossa crítica vai ao modelo formal, conteudista, prescrito e rígido, que acarreta fragmentação, gerando na vida escolar um certo distanciamento do real porque enfatiza a acumulação e não a contextualização do conhecimento, revelando, quase sempre, a falta de conexão com a prática e explicitando as contradições entre conhecimento escolar e o cotidiano dos estudantes

Já numa perspectiva multi, inter e trans disciplinar temática, o currículo se organiza com base em agrupamento das disciplinas, nos problemas concretos, nas experiências dos estudantes com base na realidade do entorno da escola. Com base em temas, o ensino e a aprendizagem são ricos e contextualizam os assuntos com base na investigação e no protagonismo, na liberdade de aprender e criar. Essa base colaborativa, interativa, 
compartilhada e integrando as TDIC revela uma possibilidade de um currículo inovador em rede de aprendizagem.

No espaço das múltiplas redes de aprendizagem conectadas, encontramos o currículo rizomático, ou seja, não tem começo, nem fim; tudo continua sempre; é o meio sendo ampliado, não é um currículo linear e os estudantes e professores juntos vão lidando com as incertezas, o imprevisto, com a reinvenção dos conceitos e do próprio modo de ser e estar no mundo, refletindo de maneira mais complexa, como se tornou nossa forma de viver no século XXI, conectando os conteúdos, conceituais, procedimentais e atitudinais, buscando na verdade das nossas humanidades valores de respeito e solidariedade em aprender juntos e misturados em prol de um mundo melhor.

O currículo não pode mais ser entendido nos limites da mera organização de conteúdos ou práticas pedagógicas, determinando lugares fixos e tempos e espaços pré-estabelecidos. A atual dinâmica social, com ênfase na presença das TDIC, aponta a necessidade do deslocamento da concepção tradicional de currículo para formas abertas capazes de acolher as diferentes experiências formativas. Assim, o currículo se estabelece como espaço para a integração de saberes e produção de novos conhecimentos.

Existem formas inovadoras de trabalhar o currículo, tal como a Web currículo que favorece a aprendizagem significativa por meio das TDIC e exige certo domínio dos recursos tecnológicos, criando situações para que o estudante seja um sujeito ativo. "Integrar as TDIC com o currículo significa que essas tecnologias passam a compor o currículo [...] essa integração deve acontecer de forma transversal” (ALMEIDA; SILVA, 2011, p. 8). Utilizar as diversas linguagens na prática pedagógica e no desenvolvimento de web currículo supõe atribuir significado e novas formas de aprender por meio desses artefatos, de forma que contribua para a formação de sujeitos autônomos, críticos e reflexivos (CRUZ, 2016, p. 36). Com a midiatização das tecnologias, o currículo se desenvolve a partir do diálogo entre pessoas, linguagens, conhecimentos e culturas.

O currículo da cultura digital traz elementos fundamentais para uma rede de aprendizagem complexa de conteúdos e significados (SILVA; OLIVEIRA, 2017). Nesse contexto, as tecnologias passam a ser ferramentas cognitivas (VALENTE, 2003) fazendo parte das atividades curriculares dos estudantes, potencializadas pelas pesquisas na web, sendo a maior riqueza da rede o potencial de interatividade, colaboração e compartilhamento e discutindo temas diversos como gênero, raça e meio ambiente; qualquer que seja a temática ou 
conteúdo, o currículo se amplia, não é uma grade e sim uma rede.

Toda rede é um caminho para o futuro e também para outras redes. A rede social de uma escola, por exemplo, possui grande capital coletivo de muitos interesses e conhecimentos significativos...compartilhando e ampliando conteúdos para resolução de problemas do cotidiano (SILVA; OLIVEIRA, 2017, p. 133).

Discutir currículo em rede é "muito mais do que apenas dinamizar e promover uma nova materialização da informação, a tecnologia digital permite a conexão de sujeitos, de espaços e/ou cenários de aprendizagem, exigindo dos mesmos novas ações curriculares em rede" (SANTOS, 2003, p. 36).

Cada instituição participante da Rede de Aprendizagem pesquisada, com suas normas e dinâmicas, permitiu acontecerem conversas, propostas e combinados, na colaboração, buscando uma expansão, gerando, por conseguinte, uma desterritorialização, saindo do modelo da árvore para o rizoma (DELEUZE; GUATTARI, 1995). Para Gallo (2008, p. 70), "um momento de fuga e criação, encarando a possibilidade de um devir".

Começando pela perspectiva interdisciplinar, a participação na rede mexeu com a organização disciplinar dos professores, envolvendo a mistura das turmas, de anos e idades diferentes, calendário e horários distintos, currículo prescrito, modelo hierárquico instituído, todos esses aspectos começaram a ser repensados para dar espaço aos rizomas que crescem pelo meio. Assim, foi crescendo a rede de aprendizagem, sem uma organização fixa, como bom rizoma não teve um começo, nem fim rigidamente estabelecido (DELEUZE; GUATTARI, 1995).

Trabalhar em rede é uma forma interessante de transgredir os sistemas, isso porque mesmo com todos os poderes que fazem o controle, demarcam as áreas, opinam sobre ele, tudo vaza e escapa (PARAISO, 2010). Na rede, os estudantes tiveram a oportunidade de trocar e socializar saberes, sem as amarras de um currículo prescrito. Pensar o currículo rizomático é refletir e agir como para produzir hastes, filamentos que parecem raízes, que se conectam e, penetrando no tronco, podendo fazê-las servir a novos e estranhos usos. Um currículo é, por natureza, um território de proliferação de sentidos e multiplicação de significados (OLIVEIRA, 2018).

O currículo inovador diz respeito àquilo que está ainda em vias de se formar: de currículos que são "realidade em potencial, que ainda não foram formados" (PARAISO, 2010, 
p. 592). Paraiso (2010) defende um currículo que se movimente, com linhas e traçados de investigação, pensar o currículo e seus escapes e variações, um currículo que pode fazer a diferença, operar para concebê-lo como território de multiplicidades, somas, desejos, desterritorializações, cultivo de alegrias e afetos. Para Oliveira (2018), um currículo é, por natureza, rizomático, porque é território de proliferação de sentidos e multiplicação de significados. Apesar de todos os poderes que fazem o controle, demarcam as áreas e opinam sobre como evitar a desorganização em um currículo e que demandam sua formatação, outros conhecimentos vão surgindo.

\section{METODOLOGIA}

Este estudo é constituído por análises qualitativas de caráter descritivo-reflexivo e teve sua organização a partir dos resultados de duas pesquisas de doutorado, que tiveram como objetos de pesquisa as redes de aprendizagem e os Estilos de Uso do Espaço Virtual em rede. Partimos da revisão bibliográfica acerca das temáticas: Novos Cenários de Aprendizagem, Estilos de Aprendizagem e Estilos de Uso do Espaço Virtual nos cenários de redes de aprendizagem; e Competências Digitais para o desenvolvimento da coaprendizagem em rede.

Este caminho metodológico busca esclarecer melhor os temas investigados, em particular, os fatores que contribuem para a coaprendizagem em rede na Educação Básica. A partir daí, aprofundaremos a compreensão sobre redes de aprendizagem como espaços para novas aprendizagens e formas de aprender; como os EA e os EUEV podem colaborar na compreensão do processo de ensino e aprendizagem na perspectiva da Coaprendizagem e suas implicações na perspectiva de um currículo mais aberto e inovador para a Educação Básica.

\section{RESULTADOS E CONCLUSÕES}

O estudo nos proporcionou a compreensão de que a Educação Básica precisa estar atenta e aberta às novas descobertas e ao conhecimento que envolvam os novos cenários de aprendizagem, as novas formas de aprender em rede e os EA e EUEV dos estudantes, como elementos essenciais no desenvolvimento das competências digitais para coaprender e cocriar em rede. Até hoje, temos um modelo de ensino que não leva em consideração as demandas dos estudantes quanto às suas formas e estilos de aprender no mundo contemporâneo. 
Promover mudanças na Educação Básica traz um dos maiores desafios na atualidade, que perpassa pelo rompimento de estruturas engessadas da prática pedagógica, que envolvem as questões didáticas, curriculares, metodológicas, de tempo e espaço etc., aliadas principalmente ao desenvolvimento tecnológico da sociedade em rede.

Entendemos que no processo de ensino-aprendizagem é possível efetivar a construção do conhecimento a partir das possibilidades dos novos cenários de aprendizagem, através das possibilidades de uso das redes digitais como espaços de aprendizagem, rompendo-se assim com o paradigma conservador, ainda existente no processo de ensinar e aprender, de forma a valorizar os EA e EUEV, em suas peculiaridades e dimensões contextuais, visando à coaprendizagem e à cocriação em rede.

Assim, entendemos que o contexto de rede de aprendizagem reúne as condições necessárias ao desenvolvimento da coaprendizagem e favorece práticas curriculares inovadoras. As redes de aprendizagem caracterizam-se como um lugar de pesquisa, participação e colaboração na construção do conhecimento e os EUEV promovem uma participação maior e mais intensa nas atividades de aprendizagem organizadas, uma vez que valorizam competências e habilidades próprias de cada estilo, ampliando as formas de aprender, pois introduzem novos elementos no processo de aprendizagem, tal como o uso de linguagem digital (narrativas) e a comunicação direta entre pares para a produção do conhecimento para a inovação curricular, despertando maior interesse e vontade de aprender, maior participação e motivação para estudar, além do crescimento da autonomia e da autoestima.

Ao analisarmos a atuação dos estudantes em rede de aprendizagem, precisamos considerar aspectos referentes à utilização da rede como ferramenta motivacional à medida que possibilita o acesso a conteúdos educacionais, estimula a pesquisa, a seleção e a sistematização de informações, na construção do conhecimento. Portanto, a motivação para aprender e para pesquisar é um dos grandes ganhos para a aprendizagem em rede.

Concluímos, assim, que as redes digitais de aprendizagem reúnem as condições necessárias ao desenvolvimento da coaprendizagem que favorecem práticas curriculares inovadoras. Ademais, uma rede digital de aprendizagem pode configurar-se como um lugar de pesquisa, participação e colaboração na construção do conhecimento e os EUEV contribuem como possibilidades para aprendizagem no contexto de rede, pois oportunizam uma participação maior e mais intensa nas atividades de aprendizagem organizadas. 
Podemos afirmar ainda que as redes digitais de aprendizagem podem inovar as formas de aprender e têm influência sobre os EA e EUEV. Nas redes, esses estilos são dinamizados, apontando principalmente para maior colaboração no processo de aprender dos estudantes. Esses estilos também interferem na dinâmica de constituição das redes, fazendo com que elas sejam mais abertas e, ao mesmo tempo, mais centrais na aprendizagem desses sujeitos.

A partir da rede de aprendizagem, é possível ampliar práticas de colaboração em rede para a Educação Básica, de forma aberta, respeitando os diferentes EA e considerando os EUEV dos estudantes propiciando uma prática pedagógica de ensino e aprendizagem inovadora, com o uso do espaço virtual na Educação Básica.

A utilização de redes digitais de aprendizagem na Educação Básica pode favorecer a exploração da Coaprendizagem, para a transformação de uma educação convencional em uma Educação em Rede, em que a participação colaborativa dos indivíduos nesta rede seja uma condição para construção e disseminação do conhecimento, considerando o que é necessário desenvolver nos estudantes, em relação aos EA e EUEV, uma vez que é possível atender às individualidades de cada estudante, dar ênfase aos processos metodológicos e ampliar os processos avaliativos em relação à construção do conhecimento do estudante.

\section{REFERÊNCIAS}

ALMEIDA, Maria Elizabeth Bianconcini de. Bases teóricas da rede de pesquisa e colaboração Universidade Escola. In: ALMEIDA, Maria Elizabeth Bianconcini et al. Rede de pesquisa colaborativa universidade escola. Recife: Editora: UFPE, 2017. p. 13-31.

ALMEIDA, Maria Elizabeth Bianconcini de; SILVA, Maria da Graça Moreira da. Currículo, tecnologia e cultura digital: espaços e tempos de webcurrículo. Revista e-curriculum, São Paulo, v. 7, n. 1 Abril/2011. Disponível em: http://revistas.pucsp.br/index.php/curriculum. Acesso em: 18 mar. 2020

ALONSO, Catalina Maria; GALLEGO, Domingos José; HONEY, Peter. Los estilos de aprendizaje: procedimientos de diagnóstico y mejora. Bilbao: Mensajero, 2002.

BARROS, Daniela Melaré Vieira. Estilos de aprendizaje y medios didácticos en contextos virtuales. Orientadora: Catalina María Alonso García. 2011.400 f. Tese (Doutorado) Faculdade de Educação, Universidade Nacional de Educação a Distância, Madri, 2011.

BARROS, Daniela Melaré Vieira. Estilos de Coaprendizagem e alguns indicadores das competências digitais. Educación, Lisboa, Portugal, Vol. XXIII, N 45, pp. 91-105, septiembre 2014. 
BEDIN, Everton. Aprendizagem Colaborativa, Troca de Saberes e Redes Sociais: tríade na Educação Básica. Revista Brasileira de Ensino de Ciência e Tecnologia, Curitiba, v. 10, n. 2, 2017. Disponível em: https://revistas.utfpr.edu.br/rbect/article/view/3922. Acesso em: 16 mar. 2020.

CRUZ, Wermes Dias Damascena. Narrativas Digitais e construção do conhecimento. Orientadora: Maria Elizabeth Bianconcini de Almeida. 2016. 148 f. Dissertação (Mestrado em Educação: Currículo) - Pontifícia Universidade Católica de São Paulo, São Paulo, 2016. DEGRANDIS, Fernando; MARQUES, Cíntia Bueno. Inovação curricular: um desafio possível. Educação Por Escrito, Porto Alegre, v. 9, n. 1, p. 118-133, jan.-jun. 2018.

DELEUZE, Gilles; GUATTARI, Félix. Mil Platôs: capitalismo e esquizofrenia, vol. 1. São Paulo: Ed. 34, 1995.

GALLO, Sílvio. Deleuze \& a Educação. Belo Horizonte: Autêntica, 2008.

MARTINO, Luís Mauro Sá. Teoria das mídias digitais: linguagens, ambientes, redes. 2. ed. Petrópolis, RJ: Vozes, 2015.

MASETTO, Marcos Tarcísio. Mediação pedagógica e o uso da tecnologia. In: MORAN, José Manuel; MASETTO, Marcos Tarcísio; BEHRENS, Marilda Aparecida. Novas tecnologias e mediação pedagógica. Campinas, SP: Papirus, 2000. p. 133-173.

OBLINGER, Diana. Space as a Change Agent. In: OBLINGER, Diana (Org.). Learning Space. EDUCAUSE, 2006. Disponível em:

https://www.educause.edu/ir/library/pdf/pub71011.pdf. Acesso em: 25 mar. 2020.

OKADA, Alexandra. Colearn 2.0 - coaprendizagem via comunidades abertas de pesquisa, práticas e recursos educacionais. Revista e-Curriculum, [S.1.], v. 7, n. 1, abr. 2011. ISSN 1809-3876. Disponível em: https://revistas.pucsp.br/curriculum/article/view/5813. Acesso em: 12 mar. 2020.

OKADA, Alexandra. Engaging Learning Communities in Producing, Adapting, Sharing and Disseminating Open Educational Resources. 19th International Conference on Learning. The International Journal of Learning, 2012.

OKADA, Alexandra. Competências-chave para coaprendizagem na era digital: fundamentos, métodos e aplicações. 2. ed. Santo Tirso: White Books, 2014.

OLIVEIRA, Cláudia Simone Almeida de. Redes de aprendizagem no contexto das tecnologias digitais: aprender e compartilhar na multiplicidade de saberes de um espaço rizomático. Orientador: Sérgio Paulino Abranches. 2018. 380 f. Tese (Doutorado em Educação Matemática e Tecnológica) - Universidade Federal de Pernambuco, Recife, 2018.

OOI, Keng-Boon; HEW, Jun-Jie; LEE, Voon-Hsien. Could the mobile and social perspectives of mobile social learning platforms motivate learners to learn continuously?. Computers \& Education. Estados Unidos, v. 120, p. 127-145, 2018. 
Programa de Pós-Graduação em Educação: Currículo

PARAISO, Marlucy Alves. Diferença no currículo. Cad. Pesquisa, São Paulo, v. 40, n. 140, p. 587-604, Aug. 2010. Disponível em:

http://www.scielo.br/scielo.php?script=sci_arttext\&pid=S0100-

15742010000200014\&lng=en\&nrm=iso. Acesso em: 15 mar. 2020.

PRENSKY, M. Digital natives, digital immigrants. On the Horizon, v. 9, n. 5, out. 2001. Disponível em:

http://www.marcprensky.com/writing/Prensky\%20\%20Digital\%20Natives, \%20Digital\%20Im migrants\%20-

\%20Part1.pdfhttp://www.marcprensky.com/writing/Prensky\%20\%20Digital\%20Natives,\%20

Digital\%20Immigrants\%20-\%20Part1.pdf. Acesso em: 20 mar. 2020.

SANTOS, Edméa Oliveira dos. Novas práticas curriculares na educação a distância.

Comunicação \& Educação, São Paulo, v. 26, p. 35 a 42, jan./abr. 2003.

SILVA, Maria do Rozario Gomes da Mota. Redes digitais e estilos de uso do espaço virtual: atuações e inovações nas formas de aprender. Orientador: Sérgio Paulino Abranches. 2020. 134 f. Tese (Doutorado em Educação Matemática e Tecnológica) - Universidade Federal de Pernambuco, Recife, 2020.

SILVA, Maria do Rozário Gomes da Mota; OLIVEIRA, Cláudia Simone Almeida de. Participação de estudantes em uma rede de pesquisa colaborativa Universidade escola: Interação e colaboração na produção do conhecimento. In: ALMEIDA, Maria Elizabeth Biancocini; ABRANCHES, Sérgio Paulino; LEMOS, Silvana; MUÑOZ, Cleide (Orgs.). Rede de pesquisa colaborativa Universidade Escola. Recife: Editora da Universidade Federal de Pernambuco, 2017. p. 129-141.

SILVA, Maria do Rozario Gomes da Mota; OLIVEIRA, Cláudia Simone Almeida de; ABRANCHES, Sérgio Paulino. Estilos de uso do espaço virtual e redes digitais de aprendizagens: interatividade, colaboração e inovação curricular. In: VI Seminário Webcurrículo. Anais. São Paulo, 2019.

TERÇARIOL, Adriana Aparecida de Lima; BARROS, Daniela Melaré Vieira. Os Estilos de Uso dos Espaços Virtuais e as Redes Sociais na Pedagogia: Um Estudo Exploratório. Journal of Learning Styles, v. 10, n. 20, p. 321-356. ISSN: 2232-8533. 2017. Disponível em: http://revistaestilosdeaprendizaje.com/article/view/1067. Acesso em: 22 mar. 2020.

VALENTE, José Armando (Org.). Formação de educadores para o uso da Informática na escola. Campinas, SP: UNICAMP-NIED, 2003.

VALENTE, José Armando. Educador quer redes sociais no currículo escolar. 2011.

Disponível em: http://ultimosegundo.ig.com.br/educacao/educador+quer+redes+ sociais+no+curricul o+escolar/n1238187320827.html. Acesso em: 16 mar. 2020.

WANG, Jian. Application of Blending Learning Based on Network: Learning Space in Teaching Design of Digital Art. Revista Internacional de Tecnologias Emergentes na 
Programa de Pós-Graduação em Educação: Currículo

Aprendizagem (iJET), [Sl], v. 14, n. 03, p. pp. 177-189, fev. 2019. ISSN 1863-0383.

Disponível em: https://online-journals.org/index.php/i-jet/article/view/10107. Acesso em: 15 mar. 2020.

WHITE, David; LE CORNU, Alisson. Visitors and Residents: A new typology for online engagement. First Monday, v. 16, n. 9, 5 set 2011. Disponível em:

http://firstmonday.org/ojs/index.php/fm/article/view/3171/3049. Acesso em: 10 mar. 2020.

\section{NOTAS}

${ }^{1}$ Coaprendizagem é uma aprendizagem aberta colaborativa para a construção de conhecimento acessível a todos através das novas tecnologias. Ou seja, é uma aprendizagem em rede, de forma colaborativa. Esta definição tem como base os estudos de Okada $(2012,2014)$.

${ }^{2}$ Prensky (2001) utiliza o termo "nativo digital" para designar os grupos de jovens e adolescentes que cresceram em um marco tecnológico digital, que dispõem naturalmente de habilidades para utilizarem esses meios e que são fluentes na linguagem digital dos computadores, dos videogames e da internet. White e Le Cornu (2011) propõem a substituição do termo nativos digitais, defendido por Prensky (2001), por residentes digitais. Os autores procuraram propor uma alternativa que lhes permitiu colocar uma metáfora diferente à subjacente de "aprendizagem de língua"; a metáfora de "lugar" no centro do palco e oferecer a analogia "Residentes" como alternativa aos Nativos Digitais. Para os autores, "residentes" cumprem um propósito semelhante ao mapear o envolvimento dos indivíduos com a Web.

Recebido em: 15/04/2020

Aprovado em: 30/06/2020 